\title{
Micromobilization through live streaming: the Elin Ersson case
}

Mona Khattab

Live streaming is a media innovation that enables individuals to communicate with thousands of social media users instantly. This article explores how live streaming is used to support micromobilization in the context of social activism. It focuses on the case of live streaming from an airplane by the Swedish activist Elin Ersson. This live stream aimed to prevent the deportation of an Afghani asylum-seeker from Sweden. A qualitative content analysis of both the live streamed video and the viewers' responses is undertaken. Two typologies for Social Behavior in live streamed micromobilization are developed, namely Digital Support Behavior (DSB) and Digital Rejection Behavior (DRB). Analyzing the content of the live stream and the viewers responses according to these typologies reveals that live streaming can support individualized micromobilization.

Keywords

live streaming, micromobilization, digital support behavior (DSB), digital rejection behavior (DRB), social network sites (SNS), facebook

\section{INTRODUCTION}

Live streaming can be used by individuals to communicate with thousands of other social media users. It couples the individuality of outreach that characterizes social media with an immediacy of communication. This article explores how live streaming is used within the context of social activism. A case study central to the article is Elin Ersson's live streaming of the deportation of an Afghani asylum seeker from Sweden. This case exemplifies the power an individual activist has to use live streaming in order to digitally mobilize support for a social cause.

On July 23, 2018, Elin Ersson, a 21-year old Swedish student activist, boarded a plane at Gothenburg airport in order to stop the deportation of an Afghani asylum-seeker. She stood up, knowing the captain could not take off unless all passengers were seated. She insisted she would neither sit down nor leave the plane unless the asylum-seeker left the plane. Enduring the berating remarks of some passengers and the threats of flight attendants, Ersson stood her ground until she gained the support of an increasing number of passengers, including an entire football team, who stood up to join her protest. Eventually, Ersson was reassured that the asylum-seeker was escorted back to the airport and she left the plane. When Ersson initially approached the man to be deported, a security officer pushed her away. The idea of capturing a video turned into a live stream, and, in the process, Ersson produced what may be considered as one of the more recent landmarks of using this mode of dissemination to support social activism.

Ersson's video received more than 5 million views. Viewers commented on her video during and after the live stream. The language used throughout the 
live stream was mostly English, with some minimal use of Swedish and Turkish. The live stream, lasting 14 minutes and 6 seconds is currently posted on Ersson's Facebook page (Ersson, 2018; Ersson, n.d.).

News reports and analysis of this case largely cited social media reactions. Asia News Monitor writes "The video shows the student attracting support and applause but also hostility from other passengers" (Asia News Monitor, 2018, p. 4). Similarly, BBC News writes, "Social media reactions were largely supportive of her action, although some people are accusing her of grandstanding" ("Elin Ersson: Student fined," 2019, p. 9). DW goes into detail, narrating the video Ersson posted, thus emphasizing the visual impact of the live streaming, "A video is posted on Facebook. It is a close-up of a young woman with a flushed face, blonde hair and dark-green glasses. [...] She is speaking English with a Swedish accent into her smartphone camera and live streaming the scene on Facebook" (Pham \& Hakim, 2019, p. 1). The Guardian stresses that Ersson's emotional responses were filmed, "She finally breaks down on the film, not from the hostility of a handful of people, but from the uplifting support of other passengers" (Saner, 2018, p. 4).

Ersson's video has sparked polarized reactions that mirror the current European controversy about migration and asylum. At a time when "the most tur- bulent political areas in recent years has been asylum policy," any public act related to the issue attracts attention (Andersson, Bendz, \& Olofsdotter Stensöta, 2018, p. 307). This has also more recently become true in Sweden, which was for a long time the country that welcomed the largest number of asylum-seekers (EIU, 2016). Sweden's policies changed dramatically in 2015, after record asylum approvals in 2014. Reasons cited for the change of policy include economic and conservative political pressure, and a lack of support or reciprocal asylum policies in other European countries (Parusel, 2016).

In Sweden, Ersson's live streaming is typical of the resistance tactics used by human rights and immigration activists when protesting against changing political ground in Swedish asylum policy. Her video rapidly became emblematic of the conflict. She gained relatively strong support online but had to face repercussions from her government because of a perceived violation of air-travel regulations. A filmed adaptation of Ersson's protest on the aircraft was produced in early 2019, as a means of support before her trial (Norström, 2019). On her Facebook page, Ersson, who refers to herself as an activist (Sittstrejken i Göteborg, 2018), posted on her Facebook page three hours before she went to the aircraft stating that it was not illegal to refuse to sit down before a flight took off. Nevertheless, Ersson was fined 3,000
SEK. Furthermore, the deportation she aimed to stop eventually took place at a later date ("Elin Ersson: Student fined," 2019). The video, therefore, is a testimony to discrepancies, not only among the public, but also between governmental decisions and public opinion, nationally and internationally.

Furthermore, the incident pinpoints the potential of live streaming in the context of micromobilization. The discourse around filming was central to the relatively short video, thus highlighting its importance as a factor that impacted the behavior of those who were present. The flight attendant and those who opposed Ersson's stance had two requests during the live stream: that she should sit down and that she should stop filming (Ersson, 2018, 0:12; 1:37; 2:06; $4: 07 ; 4: 36 ; 5: 19)$. The insistence on ending the live stream underlines its significance. It is not unrealistic to hypothesize that live streaming contributed to shifting the balance of power to Ersson's favor. Her position might have been considerably weaker if the flight crew were not aware that their actions would be recorded and documented, and potentially scrutinized by a large number of viewers.

\section{RESEARCH QUESTION}

This article explores how live streaming facilitates micromobilization in the context of social activism. To address this research question, it employs a 
qualitative content analysis of both Elin Ersson's live stream and the comments posted in relation to it.

LIVE STREAMING AND MICROMOBILIZATION

Waldfogel (2017) maintains that the disruptive impact of new digital technologies cannot be underestimated. With increased access to opportunities for communication, individuals can now play the role of agenda setters, initiating responses and attempting to channel public opinion. Social media abound in examples of users who have surpassed major corporations and entities in their outreach by accumulating millions of followers on various platforms (Marwick, 2018). Indeed, the use of terms such as social media influencer or microcelebrity refers to what Cirucci (2018) calls 'celebrification'

The potential for interaction amongst users of social media networks has also developed. With interactive features ranging from liking to commenting on individual posts, individuals also have new opportunities to measure the responses of their followers (Lysak, Cremedas \& Wolf, 2012). While skewed responses can arise from trolling and hiring respondents, the opportunity to collect and analyze public response as it develops in real time cannot be underestimated.

Wendt (2017) describes the difference between live streaming and earlier forms of television as follows: "television is a form of communication that is unidirectional, institutionalized, edited and directed towards an audience, while live streaming is bidirectional, decentralized, autonomous and contingently produced for an audience" (p. 4). While the responses of followers and commenters to live streaming are updated in real time, they relate, for the most part, to an event that has already taken place. Andén-Papadopoulos (2008) and Feldman (2005) have argued that the pervasiveness this brings about enhances the power of media to add social value to any given event. Live streaming thus redefines the relationship between digital technology and event broadcasting, introducing a new form of virtual attendance (Mueser \& Vlachos, 2018).

Live streamed videos reach their audience instantly and therefore maintain the spontaneity of live broadcasting. At the same time, live streaming adds an innovative potential for user interaction. Followers viewing a live streamed video can interact with the sender instantly. This influence can in many cases be mutual. Users on both the recording and viewing end can impact each other's feedback. The audience can, in that sense, be considered "real time distant witness[es]" (Martini, 2018, p. 4037). Users of live streams can thus explain and modify their behavior based on the feedback they receive. This can considerably boost the ability of the user who is live streaming to influence viewers.
This in turn introduces the potential for a new form of individual micromobilization, which can impact how public opinion is shaped (Hockin \& Brunson, 2018). As Martini (2018) puts it, the fact that viewers appear to each other and are simultaneously active, creates a sense of community among individual users. Martini (2018) observed that viewers of a live stream might react to each other's comments but did not leave the main live stream. In this way they formed a solid audience around the streamed event. Funke and Spering argued (in Wendt, 2017) that unlike other forms of digital interaction, live streaming provides the opportunity to observe viewers interacting while focusing on a single event that captures their attention, thus making comments posted to a live stream akin to thinking aloud.

Recent live streamed events have shed light on issues that would otherwise have needed considerably longer time to come to the foreground of public attention. These include reports of the police shootings of African-American males in the United States, notably those of Alton Sterling and Philando Castile. Castile's live streamed death was viewed over 5 million times within a week (Lehigh University, 2016). The legal consequences and potential of the videos were also controversial, as they raised questions of the right to know about police violations, and concerns for individual privacy. This problematized the space between 
the private and the public, and between surveillance and information (Stewart \& Littau, 2016). Live streaming has also been used for commercial campaigns such as Nike's \#Breaking2 athletic records campaign. In this case live streaming was argued to be instrumental in guaranteeing authenticity (Davis, 2017). Live streaming has thus been used to support credibility, whether in gruesome police shootings or in sports and commercial enterprises.

Live streaming has also been used to support terrorist acts. The public shootings at mosques in Christchurch, New Zealand raised concerns about how shooters and terrorists could use live streaming to popularize violence and spread terror. Russell (2019) explains that Facebook was compromised by its own technology as it scrambled to contain the effects of live streamed shootings in New Zealand. Live streaming terrorist acts and mass killings were considered to signal a new era of public loss of innocence (Peacock, 2019).

Public support for individual users of live streams has also been the subject of some research. Lottridge et al. (2017) argue that live streaming has become pervasive, describing it as a 'third wave' of teenagers' fascination with selfies. The significance of live streaming increases with its versatility and its immediate connection to the younger generation.

Because of the potential for individual use, and for immediate authentication, live streaming became a method of choice for protests, as demonstrated during both the Arab Spring (Thorburn, 2014) and the protests at the site of Dakota Access Pipeline (Martini, 2018), which strategically used live streaming to gain support for their causes. Chen (2014) considers that increased viewing of live streams indicates that live streaming will be an important feature of activism in the future. Given the potential that live streaming introduces for virtual attendance and interaction, as well as enhancing authentication, this study explores how live streaming can support micromobilization in the context of social activism.

\section{SOCIAL SUPPORT BEHAVIOR (SSB)}

To address this article's research question, I use the concept of Social Support Behavior (SSB). This concept was developed in social behavioral and psychometric research to understand behavioral patterns that indicate social support (Barrera \& Ainlay, 1983; Gottlieb, 1978; Pattison, 1977). Social support is considered multidimensional and, as a result, several studies have attempted to shed light on its elements (Curton \& Russel, 1990). According to Cobb (1976), social support is "information leading the subject to believe that he is cared for and loved, esteemed, and a member of a network of mutual obligations" (p. 300). Kaplan et al. (1977) add an individualized aspect by arguing that social support depends on the degree to which an individual's social needs are fulfilled through interaction. A key feature of social support is its combination of verbal and nonverbal modes of communication. The use of both modes is understood to minimize uncertainty and enhance the recipient's "perceptions of personal control in one's experience" (Albrecht \& Adelman, 1987, p. 77).

Several categorizations have been used to classify SSB patterns. Tolsdorf, in 1976, divided SSB into tangible, intangible, advice, and feedback behavior. Perhaps the most general overarching classification was introduced by Pattison in 1977 who discussed social support in social therapy. Pattison divided this into two main categories: (1) Instrumental support: which denotes tangible support such as financial or physical aid; (2) Affective support: which denotes immaterial support such as reinforcement, recognition, and esteem.

Other studies use alternative categories to analyze SSB (cf. Gottlieb, 1978; Streeter \& Franklin, 1992; Hirsch, 1980 and Cohen \& Hoberman, 1983). Mitchell and Trickett (1980) summarized previous research and outlined four modes of SSB: (1) Emotional support; (2) Task-oriented assistance; (3) Communication of expectations, evaluations, and shared world view; (4) Access to new and diverse information and social contacts. Three years later, Barrera and Ain- 
lay (1983) expanded Mitchell and Trickett's work to develop six categories of SSB. These were divided according to degrees of intimacy and material assistance, as follows: (1) Material aid: providing tangible materials in the form of money and other physical objects; (2) Behavioral assistance: sharing of tasks through physical labor; (3) Intimate interaction: traditional nondirective counseling behaviors such as listening, caring, expressing esteem and understanding; (4) Guidance: offering advice, information, or instruction; (5) Feedback: providing individuals with feedback about their behaviors, thoughts, or feelings; (6) Positive social interaction: engaging in social interactions for fun and relaxation (Barrera \& Ainlay, 1983).

According to Ko, Wang, and Xu (2013), Social Network Sites (SNS), and in particular blogs, facilitate SSB. Basing their argument on the notion that social support is a daily interactional or communicative process, they elaborate that "the interactive or communicative process through which bloggers reveal their moods, everyday lives, experiences, or other information, as well as the audience response posted in the comment box, can be considered an act of social support" (p.194). It is therefore interesting to explore what kind of SSB is engaged in during live streaming, and how this in turn facilitates micromobilization.
METHODOLOGY

I undertook a qualitative content analysis of Elin Ersson's live streamed video and its viewers' responses. I used NVivo 12 to gather and analyze commentary data and form word maps highlighting the most common key words. In order to explore the importance of real-time live streaming in facilitating micromobilization, I divided data relating to the comments into two categories, namely, those posted in real time and those posted after the live stream.

To achieve a better understanding of the diversity of responses to the live stream, the analysis went beyond statistical word mapping and delved in more detail into the commentary. SSB provided the necessary tool to understand the commenters' behavior and determine the main themes arising. In order to understand the patterns of behavior displayed a content analysis of Ersson's live streamed video was also important. This in turn supported an understanding of the spectrum of reactions among commenters. Thus, the video content is analyzed focusing on the discourse and actions of the people on the aircraft, noting specifically the changes in attitude that ultimately led to support for Ersson's stance. In both the video analysis and the analysis of the comments, SSB is used to explore how live streaming facilitates micromobilization.
Research Ethics

This study adheres to ethical regulations for research in social media in Finland. All comments and reactions have been anonymized following the guidelines of the Finnish Social Science Data Archive to avoid both the direct and indirect identification of users (Data Management Guidelines, n.d.). Both the Finnish National Board on Research Integrity TENK (n.d.) and Sveningsson's model (as cited in Östman \& Turtiainen, 2016) have been used to determine the sensitivity of the personal data used. Given that Ersson's video was live streamed and subsequently publicly posted, I concluded that it was intended for public use (Kantanen \& Manninen, 2016). I exercised caution, however, with the comments that were posted to the video. I preferred to protect the users' privacy by treating their participation as implicit (Villi \& Matikainen, 2016) and, therefore, completely anonymized their identity. Anonymization was achieved by paraphrasing and collecting common words rather than quoting or specifying comments, thus rendering the words and expressions used for analysis untraceable and their users unidentifiable. 
WORD MAPPING

I grouped words related to specific concepts as they were used most frequently in (a) Realtime, and (b) Post-live streaming categories. ${ }^{1}$ The words used most in Realtime commentary expressed awe and admiration rather than specific comments addressing Ersson's behavior. They were mainly related to the following words: (a) Amazing: words such as amazing and wonderful were the most common in all exclamatory expressions; (b) Gorgeous: interestingly, several comments described Ersson as gorgeous. It is unclear whether the remarks were intended to refer to physical attributes or were a way to describe Ersson's actions as beautiful. It is worth noting here that of all 66 Realtime comments, none negatively remarked on Ersson's actions.

While the Realtime comments were unanimously supportive of Ersson's actions, the Post-live streaming comments, though still predominantly positive, included some negative responses (33 of a total 1385). The results for the word mapping of the Postlive streaming comments are as follows: (a) Strength: words such as strong, strength, and power were the most common; (b) Courage: words such as courage, courageous, heroic and heroine were repeated frequently; (c) Fascination: The word amazing was consistently used throughout the comments.

There was no strong verbal pattern amongst the negative comments $(\mathrm{n}=33)$. The main pattern questioned Ersson's actions by pointing out that the asylum-seeker who was being deported must have broken the law. The only words repeated more than once were intended to insult Ersson and describe her as unintelligent. These included the words stupid, idiot, and buffoon.

DIGITAL SUPPORT BEHAVIOR (DSB) AND DIGITAL REJECTION BEHAVIOR (DRB

Upon observing that the provision and withdrawal of support, were central to all comments, it became necessary to examine the nature of support that commenters offered or withheld from Ersson. As a result, I set out to study support as the key behavior displayed by commenters on Ersson's video, whether in real time or after the live stream. The focus on support behavior led me to adopt SSB to explore how live streaming can facilitate digital micromobilization.

In identifying forms of support, I took the following factors into consideration: (a) The nature of live streaming as a unique environment that is simultaneously immediate and distant, thus having the potential to garner emotional support but also clearly spatially too distant for instant material support; (b) The nature of social media interaction that necessitates internet access, which, in spite of increased individual access, is still based on users' socioeco- nomic ability to have internet access; (c) The nature of the topic of this specific incident, which is racially and ethnically charged as it involves European and non-Western tensions embedded in the current immigration debate; (d) The role of language, as many of the commenters are not native speakers of Swedish or English as indicated by Facebook's automatic translation feature. Nevertheless, most comments were predominantly in either Swedish or English. This perhaps increased the reliance on emoticons as a means of expression.

As a result of these considerations, certain kinds of SSB were understood to be more relevant to the nature of this study. For example, material support cannot be instant in the case of live streaming. It must be limited at the time of live streaming to the promise of material support, which includes pledging actions such as helping with legal representation if Ersson needed it, or donating money if requested, and sharing the video to spread Ersson's message. Similarly, belonging as a form of support, in this case, is also largely relevant to the nature of digitalized communication. It is manifest in clusters among commenters who support Ersson or who defend her against other commenters, as opposed to more traditional pre-digital and pre-live streaming forms of belonging that could have been more physical, such as signing up for a street protest or joining a political party. 
I therefore base the analysis of Ersson's video and the comments and reactions it received on categories I modified to formulate a typology for SSB that fits the digital environment. I refer to this new model as Digital Support Behavior or DSB. I designed the categories of DSB to address the following forms of support. These categories are based on my observation of patterns of comments in this case study, as well as previous research exploring models of SSB. The categories are as follows:

1. Empathy: showing approval. Expressed by sharing similar emotions as the poster.

2. Esteem: enhancing self-esteem. Expressed through praising the poster.

3. Belonging: inviting the recipient of support to join a group of people that share common traits. An even more intense form of belonging can be expressed by defending the poster against other commenters.

4. Information: providing information or advice that can enhance the position of the recipient of support.

5. Material: offering physical or financial support. Expressed by promising physical presence or funding.

In addition, I developed categories that reflect the opposite of DSB, namely Digital Rejection Behavior (DRB). These categories facilitate the analysis of a wider spectrum of responses to Ersson's video. This study therefore also examines categories that express negative reactions or rejection. The aim of these new categories is to reflect how live streaming facilitates micomobilization in the context of divisive and polarizing issues, such as asylum and immigration policies. My categorization of Digital Rejection Behavior (DRB) is as follows:

1. Disapproval: expressing an anger emoji or a misplaced laughter emoji in a situation that normally would not elicit laughter.

2. Questioning: showing a mild form of disapproval by questioning the rationale of the post or the facts it presents.

3. Ridicule: showing direct disapproval by mocking the post or making fun of its content or poster.

4. Anger: showing intense disapproval by critiquing the post, or responding with accusatory statements.

5. Threatening: i.e. the opposite of material support.

\section{COMMENTARY ANALYSIS}

I divided the feedback to Ersson's video into two main modes: emoticons, known as Facebook Reactions, and commentary. The commentary itself can be divided into two forms; wordless commentary that consists solely of emoticons and written commentary. Not all Facebook reactions or emoticons are straightforward. Some of them can have opposite meanings. Like (thumbs up): indicates an initial degree of approval of the post's content. Love (heart): indicates an intense degree of encouragement of the post. Haha (laughing face): indicates amusement. It is contextual, however. On the one hand, it can indicate empathetically agreeing with the post, if the post's intention was amusement. On the other hand, it can indicate ridicule, laughing at the post if its intention was serious. Wow (surprised face): indicates a strong impression of surprise. It is normally deemed positive, as in the sense of being impressed, though it can also be used less positively to denote disbelief. Sad (tearful face): indicates sadness, usually seen as empathically understanding. Anger (angry face): Indicates disapproval. It is also contextual. It can indicate empathetically agreeing with the poster's anger, or, in contrast, can indicate anger at the poster.

As of 29th of April 2019, Ersson's video was shared 53,608 times and garnered the following Facebook Reactions: 
Figure 1: Screenshot of total reactions to the video.

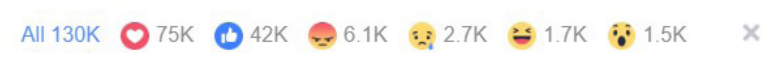

Figure 2: Screenshot of categorized reactions to the video.

The choice of reactions as a mode indicates a form of investment in the topic of the post. Nevertheless, choosing to post a written comment can be considered to express a higher degree of interest. On Facebook, comments can be displayed according to three categories, defined by Facebook as follows: (a) Most relevant: showing friends' comments and the most engaging; (b) Newest: showing all comments, with the newest comments first; and (c) Realtime Comments: showing comments at the moment when they appeared in the video.

Digital Support Behavior (DSB)

The analysis of DSB is carried out for (a) comments posted in real time during the live streaming and (b) comments posted after the live streaming.

(a) Realtime comments. All Realtime comments were positive. Esteem and Belonging were the two most visible categories of DSB. Belonging is evident as several commenters said they were "with" Ersson. Many comments displayed belonging by using the pronoun "we" to refer to Ersson as belonging to their group. Esteem was clear in the repetition of adjectives such as awesome, and descriptions of Ersson as strong and powerful. Given the short duration of the live stream, there were much fewer Realtime comments $(\mathrm{n}=66)$ than Post-live streaming comments $(\mathrm{n}=1451)$.

(b) Post-live streaming comments. The Post-live streaming comments show more variety, displaying all categories of the DSB model used in this article. Moreover, there are comments that clearly fit the negative DRB model, although they are outnumbered by the positive comments.

Empathy is evident when commenters express their emotive responses to Ersson's actions. Some commenters stated that they cried when they watched Ersson and that she brought tears to their eyes, thus highlighting empathic reactions that parallel her actions. Several comments fall under the category of Esteem, as they focus on praising Ersson's actions, thus indicating that she is held in high esteem by the commenters. Many of those comments repeatedly describe her as brave, with encouraging comments along the nature of "well done," saluting her and showing admiration. Belonging is exemplified as several commenters use the pronoun "we" to refer to Ersson as part of their group. Some openly encourage her by stating that they support her, thus bringing her in as a member of her group of supporters. Informational support is more tangible. Some commenters provide Ersson with information about other refugees. Others provide information about refugees from other countries. Some share the picture of the asylum-seeker she held in the video. Material support is illustrated as some commenters promise to support Ersson in case she is in legal trouble because of her actions, and invite her to share any problems she might face in the future with the viewers of the live stream.

\section{Digital Rejection Behavior (DRB)}

Disapproval is mainly expressed when viewers post negative emoticons such as angry or laughing faces without other comments. Their lack of commentary can construe passive aggression. Questioning is seen when some commenters ask Ersson whether she knew if the asylum-seeker was deported for a reason. Others asked whether she considered that he might have committed a crime that deserves deporting. Rejection behavior can employ ridicule. One of the 
most common words indicating DRB in the commentary was the word "buffoon." Other commenters add words indicating laughter, such as "hahaha." In other examples, commenters sarcastically suggest that Ersson take the asylum-seeker to her home.

An interesting example uses Ridicule to express Belonging. One commenter defends Ersson by criticizing another commenter, who had posted an Angry emoji to comments that were favorable of Ersson. This commenter used Ridicule, to mock the commenter who was angry with Ersson. This is an interesting example of how the categories of support and rejection apply to the comments posted as reactions to original comments.

Anger, is more likely to occur in disagreement. One commenter shows an example of Esteem by commending Ersson for fighting injustice. This prompts another commenter to disagree, displaying Questioning in the notion of injustice, thus indirectly displaying a rejection of Ersson's actions. Some Threatening behaviour is evident when a few commenters command Ersson to sit down. Some even imply that she deserves whatever legal repercussions she might face.

We can infer from this analysis that the reactions to Elin Ersson's live stream are overwhelmingly supportive. A total of 121,200 positive Facebook reaction emoticons are posted to the video as opposed to 7,800 negative ones. The supportive and negative behaviors indicate that all the categories of DSB and DRB are present. The commentary also leans strongly towards support.

\section{VIDEO CONTENT ANALYSIS}

To analyze Ersson's video, I used content analysis to reflect on the following aspects: (1) Movement; (2) Power shift; (3) Emotional response of Ersson as a central figure, and; (4) Emotional responses of the surrounding audience. The video analysis traces the development of the live stream and explores how it facilitates micromobilization on-site, and how this is in turn reflected by cyber-micromobilization through Facebook comments and reactions.

Reflecting the typologies introduced above to categorize the digital support and rejection behaviors (DSB/DRB) Ersson receives to her live streamed video, I developed two further models of Social Support Behavior (SSB) and Social Rejection Behavior (SRB) to analyze the support/rejection Ersson receives on the airplane.

The support she receives on the airplane includes; Empathy: As Ersson stands up and refuses to sit down, she, at first, is met with curiosity (Ersson, 2018, 0:13-1:09). This is followed by considerable resistance from the flight attendant and one of the passengers (1:39-3:53). Gradually, however, empathic behavior is displayed. Esteem: Ersson receives more praise as she shows the picture of another asylum-seeker who is scheduled for deportation (7:59). More passengers gather around her and look at the picture she is holding. Support is reflected as passengers start looking at the picture. Belonging: A Turkish passenger approaches Ersson telling her that he supports her and her stance (6:32). This indicates that she is beginning to belong to a new group of supporters. Information: A passenger tells Ersson that other passengers are standing up like she did (6:58). Subsequently, more passengers volunteer to tell Ersson which door she needs to use. Later, the flight attendant notifies Ersson that she can now disembark from the plane (12:41). Material: An entire football team on the plane stands up in solidarity with Ersson (6:55) followed later by several standing passengers (10:20) showing physical and material support for her actions. We also hear clapping and cheering as passengers congratulate Ersson once the captain and airport authorities agree to let the asylum-seeker off the plane (11:36).

While strong, and ultimately effective SSB is evident in the video in support of Ersson, there is also an undeniable negativity displayed in SRB. This occurs as follows: Disapproval: At the beginning, when Ersson was standing up, some of the passengers completely ignored her (Ersson, 2018, 0:57). We see mild interest from the passengers, but nothing indicates 
that she has garnered enough attention, let alone support. Questioning: The flight attendant repeatedly accused and even threatened Ersson. He told her that she was breaking the law, which she explained was not true (4:03). Ridicule: One of the passengers became vocally dismissive of Ersson and made fun of her insistence to waste everyone's time (5:05). Anger: The flight attendant angrily asked Ersson to stop filming the incident (4:40). At the same time, a passenger accused Ersson angrily of putting other passengers, including children, in a bad situation (5:13). Threatening: This is perhaps the strongest reaction of all, as a passenger knocked Ersson's phone and sent it to the floor to prevent her from filming (5:18).

The online viewers responded in real time to the video in synchronization with the reactions on the plane. Support from online commenters increased as Ersson's actions garnered support from other passengers. In contrast to the situation on the airplane, the Realtime comments to the live stream were all supportive. This contrast between on-the-ground and digital support behavior reflects how live streaming facilitated micromobilization in this case by promoting DSB and SSB.

DISCUSSION

This study introduces two new typologies aimed specifically at examining behavior that supports micro- mobilization as facilitated by live streaming. These new typologies make the analysis of live streamed videos possible both in Realtime and post-live streaming. In addition, by distinguishing between support and rejection behavior, as examined by DSB and DRB respectively, they capture the nuances of the behavior of those involved in and interacting with live streaming. The analysis underlines the positive link between live streaming and digital micromobilization and highlights clear examples of digital feedback to Ersson's activism when posted online. The distinction introduced by DRB facilitates an analysis of negative behavior and highlights its impact, if any. In this case, the support provided through various digital modes of communication, whether commentary or emoticons, significantly outnumbers rejection.

The content analysis of the video is useful because it supports a comparison between live reactions from individuals at the scene of the incident and viewers watching the incident digitally. Digital viewers are in turn divided into viewers of the real-time live stream and viewers of the post-streaming video. This analysis also reveals that the responses on location seem more negative at first, whereas online responses are more positive from the outset of both the Realtime and post-live streaming commentary. A key detail connects the physical and digital spheres of the incident: Ersson's live streaming. The negative, even at times violent, responses to the recording emphasize its significance, as it seems to curb more rejective behavior and enhance Ersson's position. The fact that Ersson was addressing the camera and narrating her story throughout the incident strengthens her reliance on digital micromobilization as much as the reactions of the flight attendant and one of the passengers show their apprehension of live streaming and its potential consequences.

The analysis in this article indicates that Ersson's ability to live stream and post a video of her activism, directly increased her potential to micromobilize. This is evident in the physical and digital feedback she receives and the consequences of her live streaming. This was further enhanced by the recognition her activism received on social media after the event.

CONCLUSION

This study investigates how live streaming can facilitate micromobilization by specifically exploring the Elin Ersson case. By comparing the supportive behavior that the live streaming brought about (via an analysis of the comments posted to the live stream), to the actual events on the plane, it is possible to see how the changing dynamics of the live streamed events impacted the online mobilization.

Exploring the video itself and the comments received through the lens of SSB facilitates this analysis. 
Models of Digital Support Behavior (DSB) and Digital Rejection Behavior (DRB) are developed to explore how different dynamics occurring in the physical and digital interaction with the live streamed event influenced and facilitated micromobilization. The lack of DRB posted during the live stream could indicate that Realtime live streaming is a more powerful form of micromobilization than videos posted after an event. At the same time, the post-live streaming commentary in this case also included very few negative comments.

Through live streaming, both the sender, Ersson, and the viewers shared a controversial and significant event, that would have been edited and controlled if it were broadcast on traditional media. Its impact gained significantly in immediacy and effectiveness because of the access that both the sender and the viewers had to the live stream itself. This study therefore concludes that live streaming has considerable potential to facilitate individualized micromobilization.

\section{Mona Khattab}

The University of Vaasa

mona.khattab@uwasa.fi.
NOTES

I translated words from other languages (mostly Swedish) into English.

\section{REFERENCES}

Albrecht, T. L. \& Adelman, M. B. (1987). Communicating social support. Newbury Park, CA: Sage Publications. Andén-Papadopoulos, K. (2008). The Abu Ghraib torture photographs: news frames, visual culture, and the power of images. Journalism, 9(1), 5-30. doi. org/10.1177/1464884907084337.

Andersson, D., Bendz, A., \& Olofsdotter Stensöta, H. (2018). The limits of a commitment? Public responses to asylum policy in Sweden over time. Scandinavian Political Studies, 41(3), 307-335. doi.org/10.1111/14679477.12125.

Auslander, P. (2008). Liveness: Performance in a mediatized culture. Oxon, OX: Routledge.

Barrera, M., Jr., \& Ainlay, S. L. (1983). The structure of social support: A conceptual and empirical analysis. Journal of Community Psychology, 11(2), 133-143.

Chen, A. (2014, December 7). Is livestreaming the future of media, or the future of activism? Daily Intelligencer. Retrieved from http://nymag.com/intelligencer/2014/12/livestreaming-the-future-of-mediaor-activism.html?src=longreads.
Cirucci, A. M. (2018), Facebook and unintentional celebrification. In C. Abidin \& M. L. Brown (Eds.), Microcelebrity around the globe: Approaches to cultures of internet fame (pp. 33-46). Bingley, UK: Emerald Publishing Ltd.

Cobb, S. (1976). Social support as a moderator of life stress. Psychosomatic Medicine, 38(5), 300-314. doi.or g/10.1097\%2Foooo6842-197609000-00003.

Cohen, S., \& Hoberman, H. (1983). Positive events and social supports as buffers of life change stress. Journal of Applied Social Psychology, 13(2), 99-125.doi. org/10.1111/j.1559-1816.1983.tbo2325.x.

Cutrona, C. E., \& Russell, D. W. (1990). Type of social support and specific stress: Toward a theory of optimal matching. In B. R. Sarason, I. G. Sarason, \& G. R. Pierce (Eds.), Wiley series on personality processes. Social support: An interactional View (pp. 319-366). Oxford, England: John Wiley \& Sons.

Cutrona, C. E., \& Suhr, J. A. (1992). Controllability of stressful events and satisfaction with spouse support behaviors. Communication Research, 19(2), 154-174. https://doi.org/10.1177/009365092019002002

David, M., Kirton, A., \& Millward, P. (2017). Castells, 'Murdochization', economic counterpower and livestreaming. Convergence: The International Journal of Research into New Media Technologies, 23(5) 497-511. doi.org/10.1177/1354856515619247 
Davis, B. (2017). Livestreaming is key to building authenticity. Marketing Week. Retrieved August 10, 2019, from https://www.marketingweek.com/livestreamingauthenticity/.

Data Management Guidelines [online]. (n.d.). Anonymisation and personal data. Tampere: Finnish Social Science Data Archive [distributor and producer]. Retrieved May 12, 2019, from https://www.fsd.uta.fi/aineistonhallinta/en/anonymisation-and-identifiers.html.

Ersson, E. (2019). Student fined for Afghan deportation protest (2019, February 18), BBC. Retrieved from https://www.bbc.com/news/world-europe-47283562.

Ersson, E. [Facebook page]. (n.d.). Retrieved from https:// www.facebook.com/elin.k.ersson?lst=100008004246 984\%3A747896273\%3A1542382277.

Ersson, E. [Facebook page]. (2018, July 23). Deportation from Gothenburg to Afghanistan [Livestreaming]. Retrieved from https://www.facebook.com/elin.k.ersson/ videos/10155723956991274/.

Feldman, A. (2005). On the actuarial gaze: from 9/11 to Abu Ghraib. Cultural Studies, 19(2), 203-226. doi. org/10.1080/09502380500077763.

Finnish National Board on Research Integrity TENK [online]. (n.d.). Ethical review in human sciences. Retrieved May 12, 2019, from https://www.tenk.fi/en/ ethical-review-in-human-sciences.
Gottlieb, B. H. (1978). The development and application of a classification scheme of informal helping behaviors. Canadian Journal of Behavioural Science / Revue canadienne des sciences du comportement, 10(2), 105115. dx.doi.org/10.1037/hoo81539.

Hockin, S. M., \& Brunson, R. K. (2018). The revolution might not be televised (But it will be lived streamed): Future directions for research on police-minority relations. Race and Justice, 8(3), 199-215. doi. org/10.1177/2153368716676320.

Kaplan, B. H., Cassel, J.C., \& Gore, S. (1977). Social support and health. Medical Care, 15(5), 47-58. doi. org/10.1097/00005650-197705001-00006

Kantanen, H., \& Manninen, J. (2016). Hazy Boundaries: Virtual Communities and Research Ethics. Media and Communication, 4(4), 86-96. doi.org/10.17645/mac. v4i4.576.

Ko, H., Wang, L., \& Xu, Y. (2013). Understanding the different types of social support offered by audience to Alist diary-like and informative bloggers. Cyberpsychology Behavior and Social Networking, 16(3), 194-199. doi.org/10.1089/cyber.2012.0297.

Lehigh University. (2016, August 3). Live-streaming crime: How will Facebook Live and Periscope challenge US privacy law? ScienceDaily. Retrieved October 15, 2019, from www.sciencedaily.com/releases/2016/o8/16080314015o.htm.
Lottridge, D., Bentley, F., Wheeler, M., Lee, J., Cheung, J., Ong, K. \& Rowley, C. (2017). Third-wave livestreaming: Teens' long form selfie. MobileHCI '17. dx.doi. org/10.1145/3098279.3098540

Lysak, S., Cremedas, M., \& Wolf, J. (2012). Facebook and Twitter in the Newsroom: How and Why Local Television News is Getting Social With Viewers? Electronic News, 6(4), 187-207. doi.org/ doi:10.1177/1931243112466095.

Martini, M. (2018). Online distant witnessing and live-streaming activism: Emerging differences in the activation of networked publics. New Media \& Society, 20(11), 4035-4055. doi. org/10.1177/1461444818766703

Marwick, A. E. (2018), The algorithmic celebrity: The future of internet fame and microcelebrity studies. In C. Abidin \& M. L. Brown (Eds.), Microcelebrity around the globe: Approaches to cultures of internet fame (pp. 161-169). Bingley, UK: Emerald Publishing Ltd.

Mitchell, R. E., \& Trickett, E. J. (1980). Task force report: Social networks as mediators of social support: An analysis of the effects and determinants of social networks. Community Mental Health Journal, 16(1), 2744. doi.org/10.1007/BFoo780665.

Mueser, D., \& Vlachos, P. (2018). Almost like being there? A conceptualisation of live-streaming theatre. International Journal of Event and Festival Management, 9(2), 183-203.doi.org/10.1108/IJEFM-O5-2018-0030. 
Norström, J. (2019, February 1). Åtalade asylaktivisten Ersson porträtteras på film. Nyheter Idag. Retrieved from https://nyheteridag.se/atalade-asylaktivistenersson-portratteras-pa-film/.

Parusel, B. (2016). Sweden's U-turn on asylum. Forced Migration Review, 52, 89-90. Retrieved from https:// www.fmreview.org/solutions/parusel.

Pattison, E. (1977). A theoretical-empirical base for social system therapy. In E. F. Feulks, R. M. Wintrob, J. Westermeyer, \& A. R. Favazza (Eds.), Current perspectives in cultural psychiatry. New York, NY: Spectrum.

Peacock, C. (2019). The New Zealand mosque massacre: 2. 'End of innocence' for media and nation. [Report]. Pacific Journalism Review, 25(1-2), 18-27. doi. org/10.24135/pjr.v25i1and2.490.

Pham, K., \& Hakim, A. (2019, January 31). Elin Ersson and Ismail $\mathrm{K}$. - How an activist tried in vain to rescue an asylum-seeker. $D W$. Retrieved from https://www. dw.com/en/elin-ersson-and-ismail-k-how-an-activisttried-in-vain-to-rescue-an-asylum-seeker/a-47295356.

Russell, J. (2019, May 15). Facebook introduces 'one strike' policy to combat abuse of its live-streaming service. TechCrunch. Retrieved from https://techcrunch. com/2019/o5/14/facebook-live-streaming-abuse-onestrike-policy/.
Saner, E. (2018, July 25). Interview: Swedish plane protester Elin Ersson: 'I knew I couldn't back down - I had to do what I could.' The Guardian. Retrieved from https://www.theguardian.com/world/2018/jul/25/ swedish-plane-protester-elin-ersson-interview-afghanistan.

Sittstrejken i Göteborg (2018, July 26). Presskonferensen i Göteborg om deportationerna till Afghanistan. [Livestreaming]. Retrieved from https:// www.facebook.com/sittstrejkeniGoteborg/videos/1888537071210177/.

Stewart, D. R. “Chip”, \& Littau, J. (2016). Up, periscope: Mobile streaming video technologies, privacy in public, and the right to record. Journalism \& Mass Communication Quarterly, 93(2), 312-331. doi. org/10.1177/1077699016637106.

Streeter, C. L., \& Franklin, C. (1992). Defining and measuring social support: Guidelines for Social Work Practitioners. Research on Social Work Practice, 2(1), 81-98. doi.org/10.1177/104973159200200107.

EIU Views Wire. (2016). Sweden economy. 'Seeking asylum-and jobs' EIU ViewsWire, November. New York, NY: The Economist Intelligence Unit Ltd.

Asia News Monitor. (2018). Sweden: Student plane protest highlights Sweden's asylum-seeker deportations. (2018, July 26). Asia News Monitor. Bangkok, Thailand: Thai News Service Group.
Thorburn, E. D. (2014). Social Media, subjectivity, and surveillance: Moving on from occupy, the rise of live streaming video. Communication and Critical/Cultural Studies, 11(1), 52-63. doi.org/10.1080/14791420. 2013.827356

Tolsdorf, C. (1976). Social networks, support and coping: An exploratory study. Family Process, 15(4), 407-417 doi.org/10.1111/j.1545-5300.1976.00407.x

Villi, M., \& Matikainen, J. (2016). Participation in Social Media: Studying Explicit and Implicit Forms of Participation in Communicative Social Networks. Media and Communication, 4(4), 109-117. doi.org/10.17645/mac. v4i4.578

Waldfogel, J. (2017). How digitization has created a golden age of music, movies, books, and television. Journal of Economic Perspectives, 31(3), 195-214. doi. org/10.1257/jep.31.3.195

Wendt, A. N. (2017). The empirical potential of live streaming beyond cognitive psychology. Journal of Dynamic Decision Making, 3(1), 1-9.doi.org/10.11588/ jddm.2017.1.33724.

Östman, S. \& Turtiainen, R. (2016). From research ethics to researching ethics in an online specific context. Media and Communication, 4(4), 66-74. doi. org/10.17645/mac.v4i4.571 